\title{
Variação Temporal da suscetibilidade erosiva no município de Boa Esperança, Sul de Minas Gerais
}

\section{The Temporal Variation of erosive susceptibility in the municipality of Boa Esperança, South of Minas Gerais}

\author{
Talyson de Melo Bolleli \\ Doutorando em Ciências da Engenharia Ambiental da EESC/USP, São Carlos- SP, Brasil \\ bolleli@usp.br \\ Derielsen Brandão Santana \\ Doutorando em Ciências Ambientais na UNIFAL-MG, Alfenas-MG, Brasil \\ derielsen@hotmail.com \\ Frederico Fabio Mauad \\ Doutor em Planejamento de Sistemas Energéticos pela UNICAMP \\ Professor Associado da EESC/USP, São Carlos-SP, Brasil \\ mauadffm@sc.usp.br \\ Matheus Lima de Andrade \\ Mestrando em Geografia na UNIFAL-MG, Alfenas-MG, Brasil \\ matheusgsmer@gmail.com \\ Allan Carlos de Andrade \\ Graduando em Geografia na UNIFAL-MG, Alfenas-MG, Brasil \\ allan.andrade@sou.unifal-mg.edu.br
}

\begin{abstract}
Resumo
Atualmente a erosão hídrica é um dos principais problemas que atinge os solos e é influenciada por diversos parâmetros, dentre os quais o uso e ocupação da terra, o relevo e as classes de solo. A determinação de ações efetivas para conservação do solo depende da habilidade dos pesquisadores em analisar, de forma integrada, os principais fatores relacionados à erosão do solo, de modo a identificar as áreas críticas e auxiliar a tomada de decisão. Muitos estudos sobre erosão são feitos utilizando a combinação dessas variáveis através de técnicas de Geoprocessamento e Sensoriamento Remoto. Nesse estudo a análise multicritérios foi utilizada para identificar a suscetibilidade à erosão hídrica no Município de Boa Esperança, situado no Sul do estado de Minas Gerais, buscando entender como as mudanças de uso do solo têm afetado a suscetibilidade da região. Para isso, procedeu a combinação dos parâmetros de uso e ocupação da terra, relevo, e, classes de solo durante os anos de 1990, 2000, 2010 e 2018. Os resultados da pesquisa demonstraram que a área de estudo apresenta suscetibilidade média a erosão hídrica na maior parte do território e que o ano de 2018 apresentou os maiores índices de suscetibilidade erosiva. Diante das análises desenvolvidas e resultados obtidos, fica evidenciada a contribuição da análise multicritérios para esse tipo de estudo e a serventia do mapa de suscetibilidade à erosão hídrica para o planejamento sustentável agrícola e ambiental.
\end{abstract}

Palavras-chave: Erosão Hídrica; Uso e Ocupação; Planejamento Ambiental; Análise Multicritério. 


\begin{abstract}
Currently, water erosion is one of the main problems affecting soils. It is influenced by several parameters, including land use and occupation, relief and soil classes. Determining effective actions for soil conservation depends on the researchers' ability to analyze, in an integrated manner, the main factors related to soil erosion so that they can be identified as critical and auxiliary decision-making areas. Many studies on erosion are carried out using combinations of these variables through geoprocessing and remote sensing techniques. In this study, a multi-criteria analysis was used to identify a susceptibility to water erosion in the municipality of Boa Esperança, located in the south of Minas Gerais, seeking to understand how changes that occur in land use affected the susceptibility of the region. For this, the authors combined the parameters of land use and occupation, relief, and soil classes during 1990, 2000, 2010 and 2018. The research results showed that a study area has medium susceptibility to water erosion in most territories. The year 2018 has the highest rates of erosive susceptibility. Given the analyzes developed and the results obtained, the contribution of multi-criteria analysis to this type of study and the usefulness of the water erosion susceptibility map for sustainable agricultural and environmental planning is evidenced.
\end{abstract}

Keyword: Water Erosion; Use Occupation; Environmental Planning; Multicriteria Analysis.

\title{
1. INTRODUÇÃO
}

Desde a colonização do território brasileiro, o setor agropecuário assumiu relevância na geração de renda e ocupação do espaço. Em razão disto, atualmente grandes extensões territoriais do país são ocupadas por cultivos agrícolas e pastagens. Muitas dessas áreas sofrem com o uso intensivo do solo e a ausência de práticas conservacionistas, o que, consequentemente, promove a degradação edáfica.

O solo é recurso essencial à vida terrestre, pois dele os seres humanos obtêm 99,7\% da sua alimentação (PIMENTEL, 2013). Apesar dessa relevância, não fica livre dos efeitos deletérios da erosão hídrica que ocasiona a perda de nutrientes, assoreamento de rios, poluição das águas fluviais e redução da fertilidade (FANG, 2020).

A erosão hídrica faz parte do ciclo hidrossedimentológico. Após o intemperismo das rochas há o processo erosivo, caracterizado pelo desprendimento, transporte e deposição de material edáfico pela ação da água da chuva (WEI et al., 2017). Os processos erosivos ocorrem naturalmente na paisagem, de forma lenta e gradual, moldando o relevo e a vegetação (BERTONI ; LOMBARDI NETO, 1990). Entretanto, as ações antrópicas têm intensificado os processos erosivos devido a ocupação desenfreada e o uso intensivo do solo (DOMAZETOVIC et al., 2019).

Diversos fatores influenciam na intensidade da erosão hídrica. São eles a classe de solo, a forma do terreno, as características das chuvas, o uso e ocupação da terra e as práticas de manejo adotadas (CHALISE ; KUMAR, 2020). Devido a magnitude de variáveis faz-se necessário o uso do ambiente digital disponibilizado pelos Sistemas de Informações Geográficas (SIG), onde é possível desenvolver análises integradas com o propósito de identificar a suscetibilidade do solo à erosão hídrica. 
Dentro do SIG, a análise multicritérios é uma das técnicas frequentemente empregadas. Essa técnica permite realizar mapeamentos temáticos, integrando variáveis e cruzando dados, buscando medidas de controle e uma melhor definição de diretrizes e ações a serem implantadas no espaço físico-territorial, fornecendo subsídios à gestão do território (HAMADOUCHE et al., 2019).

Atentando para isto, o presente artigo utilizou a análise multicritérios para identificar os índices de suscetibilidade à erosão hídrica no Município de Boa Esperança, situado na porção Sul do estado de Minas Gerais. Os critérios escolhidos foram o uso e ocupação da terra, o relevo e as classes de solo. Os critérios e os índices de suscetibilidade foram adaptados segundo o roteiro metodológico adotado por CALDAS et al., (2019) no estudo da Bacia Lagos - São João no estado do Rio de Janeiro.

\section{MATERIAIS E MÉTODOS}

\section{1. Área de Estudo}

A área de estudo possui área total de 86.340,40 há e corresponde ao município de Boa Esperança, localizado na região Sul do estado de Minas Gerais e pertence à bacia hidrográfica do Rio Grande e sub-bacia do reservatório do entorno do Lago de Furnas (GD3) (IGAM, 2010), inserindose entre as coordenadas 7650000 e 7695000 S e 402000 e 458000 O, Datum Sirgas 2000, Zona 23K (Figura 1).

O clima da região é o subtropical úmido (Cwa), segundo a classificação de Köppen (SPAROVEK et al., 2007), com inverno seco (temperaturas inferiores a $18^{\circ} \mathrm{C}$ ) e verão quente (temperaturas superiores a $22^{\circ} \mathrm{C}$ ). A temperatura média anual é de $20,8{ }^{\circ} \mathrm{C}$ e a pluviosidade média anual de $1.400 \mathrm{~mm}$. Janeiro é o mês mais quente do ano, com temperatura média de $23,6^{\circ} \mathrm{C}$; junho é o mês mais frio, com temperatura média de $17,1^{\circ} \mathrm{C}$ (CLIMATE DATA, 2020).

As unidades geológicas predominantes são o Complexo Campos Gerais, contendo Ortognaisses, intercalações de anfibolito e rochas metaultramáficas ígneas, o granito Suíte Porto Mendes, contendo granito, granodiorito e rochas ígneas e o Supergrupo Piumhi, Formação Serra da Boa Esperança, contendo Quartzito e associações de rocha metaultramáfica, metamáfica tholeiíticas e xisto (CPRM, 2014).

O domínio morfoclimático é caracterizado pela faixa de transição entre Mata Atlântica e Cerrado. No Município está localizado o Parque Estadual Serra da Boa Esperança (PESBE), unidade de conservação criada em 2007 (MINAS GERAIS, 2007). O PESBE encontra-se inserido nessa faixa de transição. Um relevo bastante acidentado, variando das chapadas planas às áreas de serras e escarpas. Nas chapadas a altitude varia de 900 a 1.100 metros e nas serras e cumes chegam a 1.400 metros. Nos relevos mais altos predominam os Campo de Altitude e a Floresta Estacional Semidecidual. 


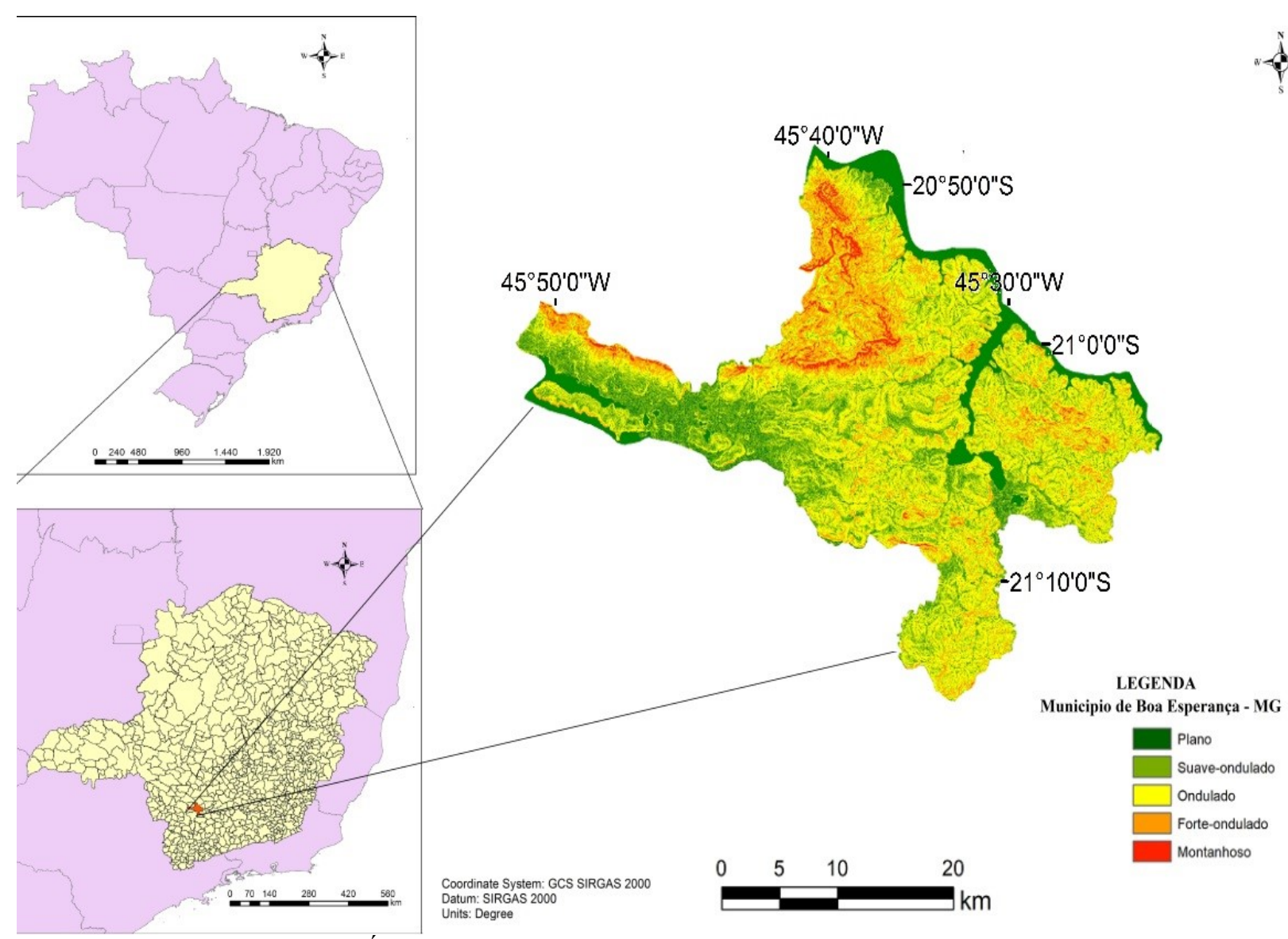

Figura 1 - Localização da Área de Estudo e Mapa de Declividade segundo a classificação da Embrapa (2018).

Fonte: elaborado pelos autores/2020.

\subsection{Elaboração dos Mapas}

O mapa de relevo foi gerado a partir do Modelo Digital de Elevação (MDE). O MDE foi obtido pelo download de imagens matriciais em formato Geotiff da área de estudo. Foram utilizadas as imagens do satélite ALOS (Advanced Land Observing Satellite), sensor PALSAR (Phased Array type L-band Synthetic Aperture Radar) com resolução espacial de 12,50 x 12,50 m, data de aquisição junho de 2011. Após esse processo, utilizou-se a ferramenta Slope do ArcGis 10.5 (Esri, 2017), classificando o relevo de acordo com a intensidade do declive em \%. As unidades de relevo foram classificadas conforme EMBRAPA (2018) na Tabela1.

Tabela 1: Valores referentes ao relevo da área de estudo.

\begin{tabular}{cccc}
\hline Relevo & Declividade (em \%) & Área (ha) & Área (\%) \\
\hline Plano & $0-3$ & 11328,06 & 13,12 \\
Suave-ondulado & $3-8$ & 25345,64 & 29,35 \\
Ondulado & $8-20$ & 34114,95 & 39,51 \\
Forte-ondulado & $20-45$ & 13602,45 & 15,76 \\
Montanhoso & $45-75$ & 1949,30 & 2,26 \\
TOTAL & - & 86340,40 & 100 \\
\hline
\end{tabular}

Fonte: Elaborado pelos autores. 
Os mapas de uso e ocupação da terra foram obtidos no site do MapBiomas (PROJETO MAPBIOMAS, 2017). Foi realizado o download dos mapas dos anos de 1990, 2000, 2010 e 2018. As classes de uso e ocupação da terra definidas foram afloramento rochoso, agricultura e pastagem (mosaicos), agricultura, floresta plantada, floresta nativa, formação campestre, mancha urbana, mata nativa, pastagem, rios e lagos e solo exposto.

O mapa digital das classes de solo foi produzido com base no Mapa de Solos do estado de Minas Gerais, escala 1:650.000 (UFV et al., 2010).

O mapa de suscetibilidade à erosão hídrica foi gerado por meio de método multicritério. Esse método foi escolhido porque possibilita integrar diversos fatores relacionados aos processos erosivos. Os fatores escolhidos foram classe de solo, declividade e uso e ocupação da terra. Foram produzidos mapas de suscetibilidade à erosão hídrica para os anos de 1990, 2000, 2010 e 2018.

Com a definição dos fatores, foram atribuídos pesos para cada um deles: 50\% para uso e ocupação da terra, $30 \%$ declividade e $20 \%$ classe de solo. O uso e ocupação da terra recebeu maior valor porque dentre as variáveis é a que sofre maior influência antrópica ao longo do tempo e a que possui o potencial mais elevado de intensificar a susceptibilidade erosiva da área.

Dentro de cada fator, foram atribuídos pesos às distintas unidades de mapeamento em escala de 1 a 9, em que quanto maior a nota, maior o risco de erosão. A Tabela 2 apresenta essas variáveis e seus respectivos pesos.

Tabela 2: Tabela de multicritérios adotados para o mapa de suscetibilidade a erosão hídrica.

\begin{tabular}{lccccc}
\hline \multicolumn{2}{c}{ Uso e ocupação da terra } & \multicolumn{1}{c}{ Declividade (em \%) } & & Classe de solo \\
\hline \multicolumn{1}{c}{ Classificação } & Veso 50 & & peso 30 & peso 20 \\
\hline Rios e lagos & $*$ & Classificação & Valor & Classificação & Valor \\
Mancha urbana & $*$ & $0-3$ & 1 & Corpos hídricos & $*$ \\
Floresta plantada & 2 & $3-8$ & 2 & Gm & 2 \\
Formação campestre & 3 & $8-20$ & 4 & LVAd & 3 \\
Pastagem & 4 & $20-45$ & 6 & LVd & 3 \\
Agricultura & 5 & -45 & 9 & PVa & 5 \\
Agropastagem & 5 & & & Cx & 5 \\
Afloramento rochoso & 7 & & & RLd & 7 \\
Solo exposto & 9 & & & 8 \\
\hline Fonte: Adaptado de Valladares et al., (2012), Pinto et al., (2014), Narra et al., (2019) e Ogato et al., (2020).
\end{tabular}

Onde * - valores desconsiderados por não haver erosão hídrica, Gm - Gleissolo háplico, LVAd - Latossolo Vermelho-amarelo distrófico, LVd - Latossolo Vermelho distrófico, PVa Argissolo Vermelho amarelo, PVd - Argissolo Vermelho distrófico, Cx - Cambissolo háplico e RLd - Neossolo Litólico distrófico. 
Os valores dos pesos foram atribuídos a partir de uma análise preliminar de cada variável na bacia e com base em estudos desenvolvidos na área de suscetibilidade erosiva e análise multicritério, como os de Valladares et al., (2012), Pinto et al., (2014), Narra et al., (2019) e Ogato et al., (2020).

Os mapas de susceptibilidade erosiva foram produzidos pela ferramenta Raster Calculator, do ArcGis 10.5 (ESRI, 2017). A equação inserida na ferramenta está apresentada a seguir:

$$
(U O \cdot 0,5)+(D \cdot 0,3)+(C S \cdot 0,2)
$$

Onde:

$U O, D$ e $C S$ denotam, respectivamente, uso e ocupação da terra, declividade (em \%) e classe de solo. A equação 1 gerou os mapas de suscetibilidade erosiva. Cada pixel recebeu um valor entre 0,5 e 8 . Os valores foram divididos em intervalos iguais: 0,5 a 2,1 - suscetibilidade muito baixa; 2,2 a 3,8 - suscetibilidade baixa; 3,9 a 5,5 - suscetibilidade média; 5,6 a 6,2 - suscetibilidade alta e 6,3 a 8 - suscetibilidade erosiva muito alta.

\section{RESULTADOS}

A figura 2 ilustra os mapas de uso e ocupação da terra do município de Boa Esperança/MG para os anos de 1990, 2000, 2010 e 2018 e a Tabela 3 as dimensões de área.

Tabela 3: Valores referentes ao uso e ocupação da terra da área de estudo durante os anos de 1990, 2000,2010 e 2018.

\begin{tabular}{|c|c|c|c|c|c|c|c|c|}
\hline \multirow[b]{2}{*}{$\begin{array}{c}\text { Uso e ocupação da } \\
\text { terra }\end{array}$} & \multicolumn{2}{|c|}{1990} & \multicolumn{2}{|c|}{2000} & \multicolumn{2}{|c|}{2010} & \multicolumn{2}{|c|}{2018} \\
\hline & Área (ha) & $\begin{array}{l}\text { Área } \\
(\%)\end{array}$ & Área (ha) & $\begin{array}{l}\text { Área } \\
(\%)\end{array}$ & Área (ha) & $\begin{array}{l}\text { Área } \\
(\%)\end{array}$ & Área (ha) & $\begin{array}{c}\text { Área } \\
(\%)\end{array}$ \\
\hline $\begin{array}{l}\text { Afloramento } \\
\text { rochoso }\end{array}$ & 4,34 & 0,01 & 8,00 & 0,01 & 26,68 & 0,03 & 76,98 & 0,08 \\
\hline Agropastagem & 5109,68 & 5,91 & 3161,97 & 3,66 & 5073,94 & 5,87 & 6554,13 & 7,59 \\
\hline Agricultura & 371,78 & 0,43 & 663,34 & 0,76 & 1556,75 & 1,80 & 7991,85 & 9,25 \\
\hline Floresta plantada & 187,55 & 0,21 & 165,35 & 0,19 & 1029,67 & 1,19 & 1254,23 & 1,45 \\
\hline $\begin{array}{l}\text { Formação } \\
\text { campestre }\end{array}$ & 2406,71 & 2,78 & 2035,82 & 2,35 & 2031,20 & 2,35 & 2137,88 & 2,47 \\
\hline Mancha urbana & 333,58 & 0,38 & 472,01 & 0,54 & 547,52 & 0,63 & 728,77 & 0,84 \\
\hline Mata nativa & 13713,16 & 15,8 & 14810,62 & 17,15 & 18589,81 & 21,53 & 16418,30 & 19,01 \\
\hline Pastagem & 53773,81 & 62,2 & 55900,72 & 64,74 & 47150,94 & 54,61 & 44784,27 & 51,86 \\
\hline Rios e lagos & 10337,27 & 11,9 & 8810,94 & 10,20 & 10251,66 & 11,87 & 6147,06 & 7,11 \\
\hline Solo exposto & 102,47 & 0,11 & 311,32 & 0,36 & 82,54 & 0,09 & 248,52 & 0,28 \\
\hline TOTAL & 86340,40 & 100 & 86340,40 & 100 & 86340,40 & 100 & 86340,40 & 100 \\
\hline
\end{tabular}

Fonte: Elaborado pelos autores.

Entre 1990 e 2010 predominaram a pastagem, a mata nativa e os rios e lagos. Em 2018 predominaram a pastagem, mata nativa e agricultura. Entre 1990 e 2018, houve a substituição das áreas de pastagem pela agricultura. A mata nativa e a floresta plantada tiveram um aumento entre 
2000 e 2010 enquanto a pastagem diminuiu. O PESBE foi criado em 2007, o que provavelmente serviu para aumentar as áreas de mata nativa e floresta plantada em sucessão às áreas de pastagem. A ampliação da agricultura sobre áreas de mata nativa e a criação do reservatório de Furnas reduziram a disponibilidade de terras para a agropecuária, o que levou muitas propriedades a avançarem para áreas mais vulneráveis da Serra, como as de declives mais intensos e matas ciliares.

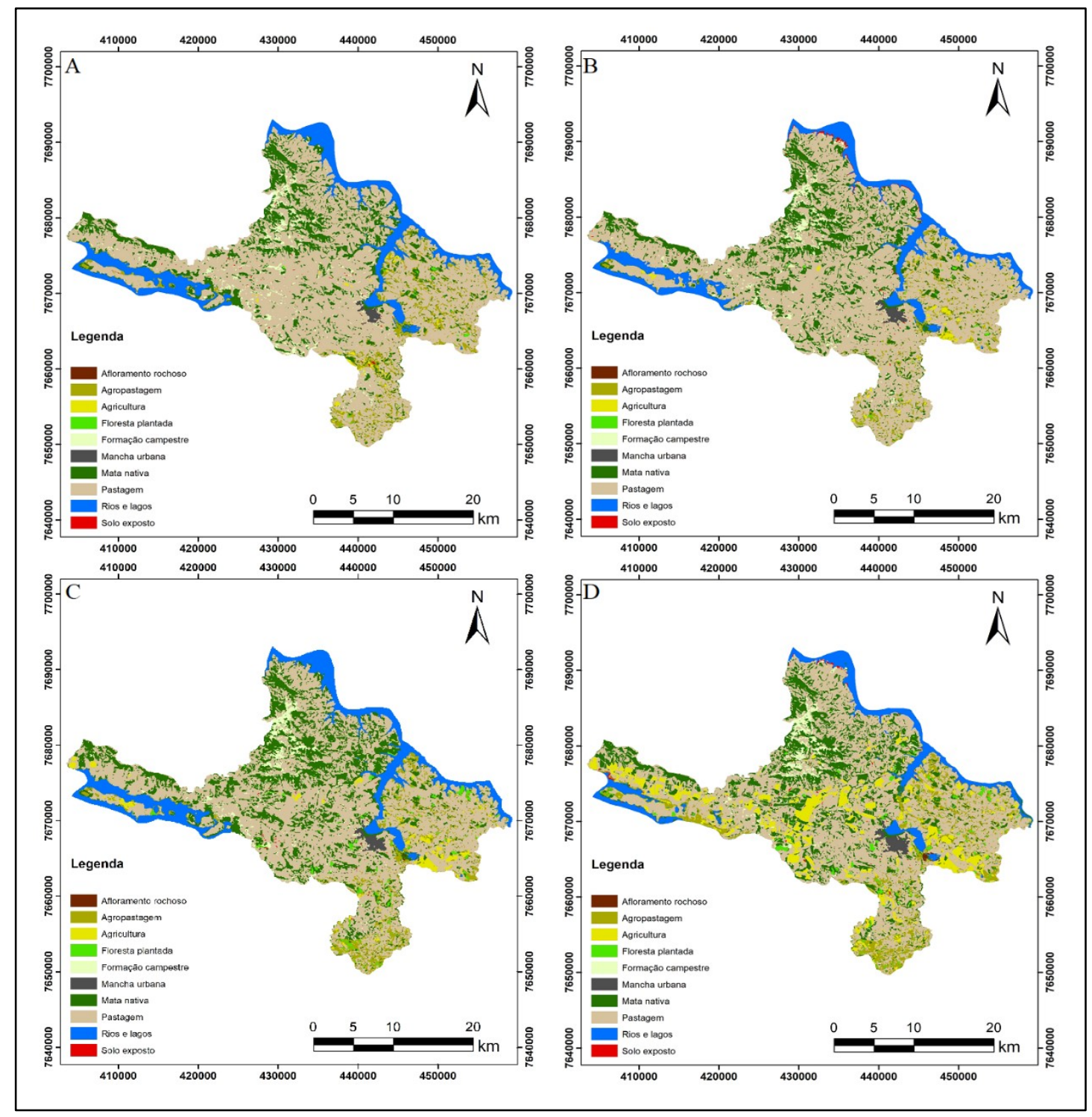

Figura 2 - Uso e ocupação da terra na área de estudo. A) 1990; B) 2000; C) 2010; D) 2018 Fonte: Elaborado pelos autores.

Pelo que se observa, as mudanças no uso e ocupação do solo as pastagens que sustentam uma pecuária extensiva foram substituídas paulatinamente pela agricultura graças ao avanço de cultivos canavieiros, cafeeiros e algodoeiros. Tal substituição foi possível devido as características do solo, clima (Tropical) e das plantas cultivadas, permitindo que a rentabilidade obtida pelos proprietários rurais não sofresse prejuízo. Aliás, seguramente a busca pelo lucro deve ter influenciado na opção. Esse dinamismo de intervenção antrópica no espaço oferece uma excelente oportunidade 
para o desenvolvimento de outras pesquisas ocupadas com a identificação dos aspectos que determinam o uso e ocupação do solo pelas atividades econômicas.

A figura 3 ilustra o mapa de classes de solo da área e a Tabela 4 os valores.

Tabela 4: Valores referentes às classes de solo da área de estudo.

\begin{tabular}{ccc}
\hline Classe de solo & Área (ha) & Área (\%) \\
\hline Corpos Hídricos & 3786,90 & 4,38 \\
Cx - Cambissolo háplico & 16760,36 & 19,41 \\
Gm - Gleissolo háplico & 4945,13 & 5,72 \\
LVAd - Latossolo Vermelho-amarelo distrófico & 1761,67 & 2,04 \\
LVd - Latossolo Vermelho distrófico & 31686,34 & 36,70 \\
PVa - Argissolo Vermelho-amarelo & 17487,66 & 20,25 \\
PVd - Argissolo Vermelho distrófico & 7362,33 & 8,53 \\
RLd - Neossolo Litólico distrófico & 2548,21 & 2,97 \\
\hline TOTAL & 86340,40 & 100 \\
\hline
\end{tabular}

Fonte: Elaborado pelos autores.

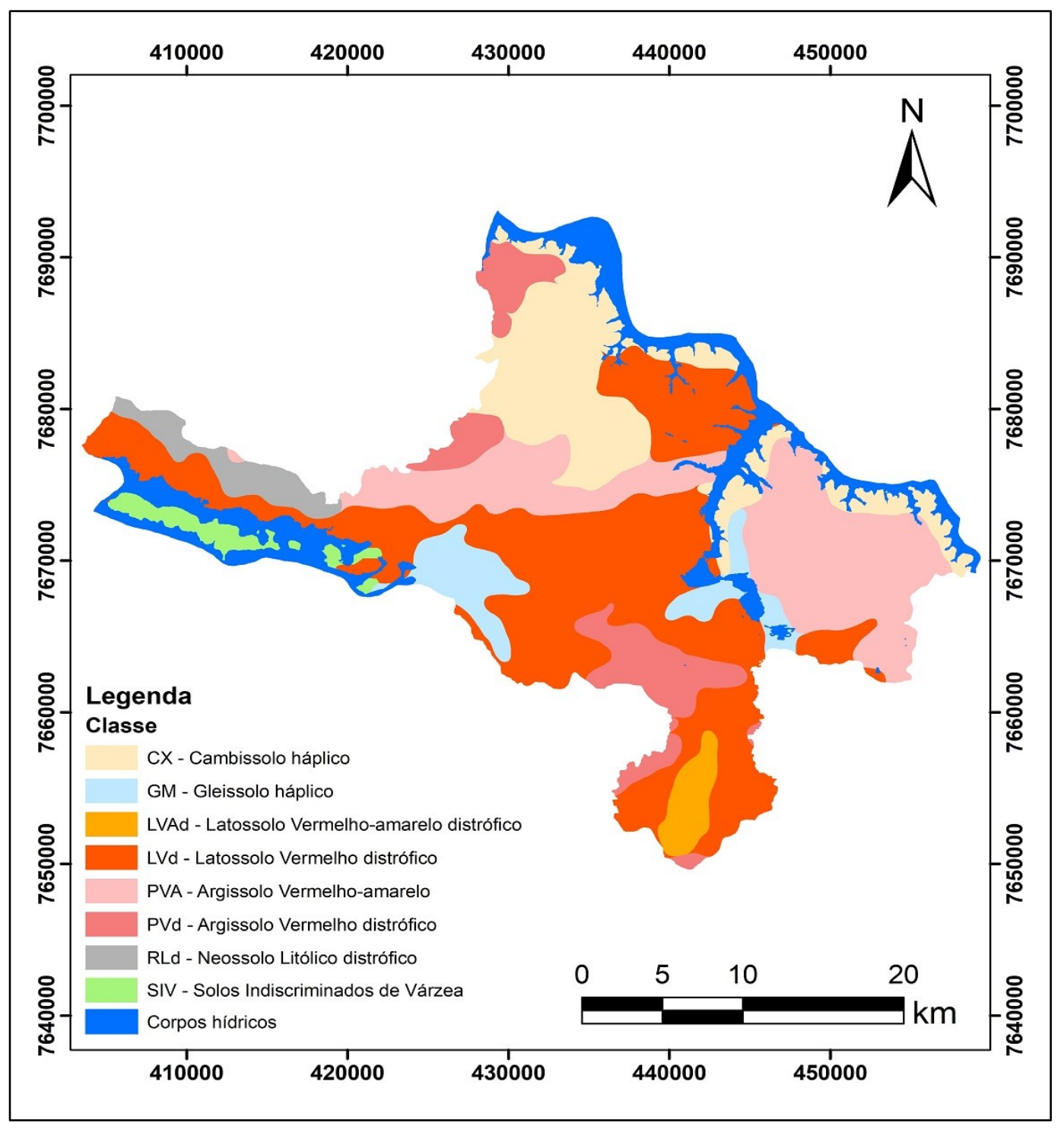

Figura 3 - Mapa de classes de solo e corpos hídricos da área de estudo.

Fonte: Elaborado pelos autores. 
Os mapas de suscetibilidade erosiva encontram-se na figura 4 e a intensidade da suscetibilidade erosiva encontra-se na Tabela 5. Segundo essa figura demonstra, é possível observar que a suscetibilidade erosiva da área não alcança patamar superior a $10 \%$ quando são consideradas as classes "alta" ou "muito alta", sinalizando que os impactos decorrentes da intervenção antrópica podem ser minimizados mediante a adoção de técnicas de manejo que evitem o escoamento concentrado da água da chuva e a exposição do solo em paralelo a adoção de um zoneamento que exclua a ocupação dos espaços das classes supracitadas.

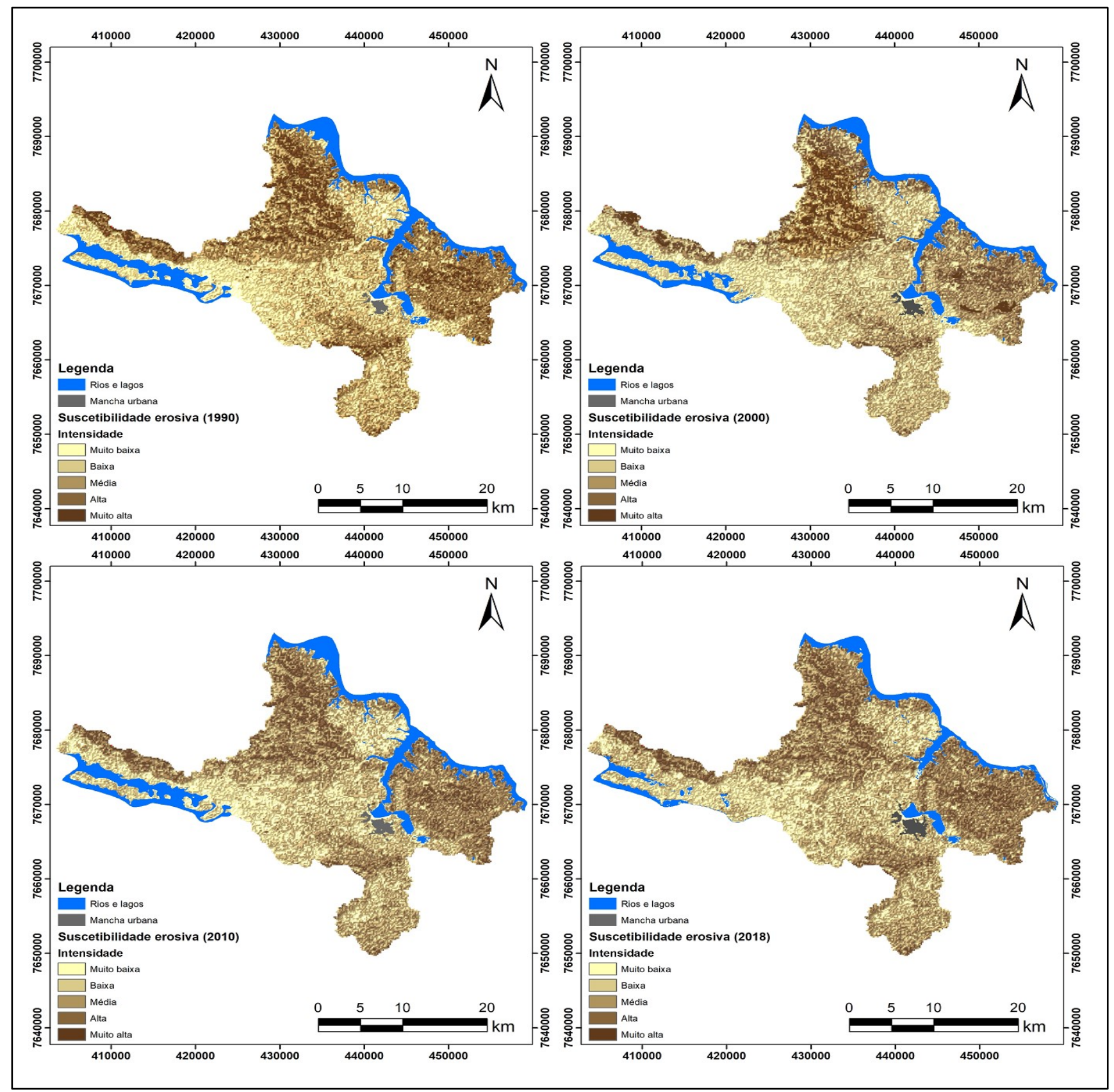

Figura 4 - Mapas de suscetibilidade erosiva da área de estudo. A) 1990; B) 2000; C) 2010; D) 2018. Fonte: Elaborado pelos autores. 
Tabela 5: Suscetibilidade erosiva segundo a intensidade na área de estudo para os anos de 1990, 2000, 2010 e 2018.

\begin{tabular}{|c|c|c|c|c|c|c|c|c|}
\hline \multirow[b]{2}{*}{$\begin{array}{c}\text { Suscetibilidade } \\
\text { erosiva }\end{array}$} & \multicolumn{2}{|c|}{1990} & \multicolumn{2}{|c|}{2000} & \multicolumn{2}{|c|}{2010} & \multicolumn{2}{|c|}{2018} \\
\hline & Área (ha) & $\begin{array}{l}\text { Área } \\
(\%)\end{array}$ & Área (ha) & $\begin{array}{l}\text { Área } \\
(\%)\end{array}$ & Área (ha) & $\begin{array}{l}\text { Área } \\
(\%)\end{array}$ & Área (ha) & $\begin{array}{c}\text { Área } \\
(\%)\end{array}$ \\
\hline Muito baixa & 7782,59 & 9,01 & 7146,80 & 9,43 & 9727,87 & 11,26 & 6369,30 & 7,37 \\
\hline Baixa & 33943,40 & 39,31 & 32911,79 & 38,11 & 33811,61 & 39,16 & 30875,56 & 35,76 \\
\hline Média & 41192,96 & 47,70 & 37266,17 & 43,16 & 35995,28 & 41,68 & 40753,72 & 47,20 \\
\hline Alta & 3009,05 & 3,48 & 7527,65 & 8,71 & 6343,76 & 7,34 & 7783,82 & 9,01 \\
\hline Muito alta & 47,25 & 0,05 & 71,54 & 0,08 & 50,66 & 0,05 & 142,84 & 0,16 \\
\hline TOTAL & 86340,40 & 100 & 86340,40 & 100 & 86340,40 & 100 & 86340,40 & 100 \\
\hline
\end{tabular}

Fonte: Elaborado pelos autores.

\section{DISCUSSÃO}

Entre 1990 e 2000 há crescimento dos locais com suscetibilidade erosiva alta provavelmente pelo aumento do solo exposto e pastagens, ou ainda pela redução dos rios e lagos devido às oscilações do nível do Lago de Furnas. Apesar do crescimento da área de mata nativa, sua expansão se deu sobre as áreas anteriormente ocupadas pelos rios e lagos ou com relevo forte-ondulado ou montanhoso. Em contraponto, o crescimento da mancha urbana, das áreas de agricultura e do solo exposto contribuem com a elevação do nível de suscetibilidade erosiva, como observado por Passos ; Klock (2019), ao verificarem que a substituição da mata nativa por áreas agrícolas aumenta a vulnerabilidade do solo.

Entre 2000 e 2010 ocorre uma expansão da área com suscetibilidade erosiva muito baixa/baixa e redução das áreas com suscetibilidade muito alta/alta. Possivelmente isto tem relação com o aumento das áreas de mata nativa, floresta plantada e rios e lagos, somado a redução das áreas de solo exposto e das pastagens. A criação do PESBE em 2007 foi fundamental para preservar áreas de mata nativa, como evidenciou Gontijo et al., (2019). O acréscimo das áreas de mata nativa oferece maior proteção ao solo, reduzindo o escoamento superficial e elevando a infiltração hídrica no solo (AMENTERAS et al., 2019).

Entre 2010 e 2018 é verificado um crescimento dos locais com suscetibilidade erosiva alta e redução dos locais com suscetibilidade erosiva baixa. Esse fato está relacionado com diversos fatores. Em nível nacional, pode-se inferir que o aumento das áreas de agricultura ocorreu em virtude da expansão da produção agrícola em todo o Brasil estimulada pela expansão econômica e aprovação do Novo Código Florestal (BRASIL, 2012). Nesse contexto registra-se ainda uma redução das faixas de mata ciliar, o que causou o assoreamento de muitas nascentes e a diminuição dos cursos d'água. Em nível local, áreas de agricultura, pastagem e solo exposto avançaram sobre áreas de mata nativa e rios, como vistos na figura 2 e no estudo desenvolvido por Sparovek et al., (2011).

Entre 2015 e 2017 a diminuição da precipitação no Sudeste (CPRM, 2017) provocou a baixa no volume dos rios e o desaparecimento das nascentes. Essa escassez nas chuvas repercutiu por toda a porção Sul do estado de Minas Gerais, fazendo com que muitas nascentes secassem ou diminuíssem de volume, favorecendo a substituição da vegetação arbórea por pastagem para o gado, solo exposto 
e principalmente agricultura, conforme se observa na tabela 2. O solo exposto aumentou principalmente nas margens dos córregos de água que secaram, permitindo que as propriedades rurais expandissem as atividades agropecuárias e a silvicultura, como atestam o acréscimo das áreas de floresta plantada e a redução da mata nativa.

Entrementes a isto, os resultados obtidos demonstram que a suscetibilidade erosiva média predomina na área estudada nos quatro períodos analisados. A suscetibilidade erosiva muito alta ocorre em áreas de solo exposto e declives acentuados; a suscetibilidade erosiva média ocorre em áreas de mata nativa com relevos montanhosos e Cambissolo háplico; e, a suscetibilidade erosiva muito baixa ocorre em áreas de mata nativa ou no entorno de rios e lagos e com relevo plano.

Também foi possível constatar que as ações antrópicas influenciam diretamente na suscetibilidade erosiva, pois a substituição da mata nativa por pastagem e solo exposto aumenta a vulnerabilidade do solo frente a erosão hídrica e a retirada de cobertura vegetal acompanhada pelo pisoteamento do gado aumentam a compactação do solo, reduzindo a força coesiva das partículas e a capacidade de infiltração da água, intensificando o escoamento superficial e os processos erosivos. Assim, é evidente a importância de se preservar a mata nativa e adotar práticas de manejo conservacionista, principalmente em locais de declividade elevada, nos quais a velocidade do escoamento superficial é potencializada, como demonstrado no trabalho de Corrêa et al., (2016).

Não obstante a isto, verifica-se que as áreas analisadas ainda não possuem problemas graves relacionados a erosão do solo em sua maioria, havendo tempo para implementar-se um zoneamento e um plano de ordenamento territorial que disciplinem o uso e ocupação do solo.

\section{CONCLUSÕES}

Após o término das análises e da apreciação dos resultados obtidos com a pesquisa é possível emitir algumas considerações finais sobre a área de estudo, metodologia adotada, cenários identificados, informações obtidas e perspectivas que se abrem para o prosseguimento de ações semelhantes noutras localidades.

Iniciando pela área de estudo e a digital humana sobre o espaço, fica perfeitamente claro a influência que as intervenções antrópicas exercem sobre a paisagem, sobretudo agravando as suscetibilidades e comprometendo a qualidade dos atributos ambientais. Diante disto, conclui-se com relação a isto que nenhuma metodologia, inventário ou monitoramento terá sucesso se não for acompanhada pela mudança de paradigmas no comportamento humano, despertando a atenção da sociedade para as consequências de seus atos.

Ainda com relação a localidade elegida de estudo fica notória a articulação que existe entre todas as variáveis que compõem um determinado cenário, pois, como foi possível verificar através 
das condições estabelecidas, por exemplo, pela declividade ou precipitação, repercutem por sobre os demais elementos constituintes da paisagem.

Com relação a metodologia adotada na pesquisa, fica estabelecida a contribuição que proporciona a estudos dessa natureza e a relevância que possui, pois, o emprego do modelo multicritério aliado aos SIGs demonstrou-se eficiente na geração de mapa de suscetibilidade à erosão hídrica, combinando variáveis de fácil obtenção, demostrando ser uma ferramenta simples, rápida, prática e de baixo orçamento.

Acerca do objeto elegido para estudo, constata-se que as áreas com solo exposto e declividades mais elevadas apresentaram maior suscetibilidade erosiva e áreas com mata nativa e declividades mais baixas apresentaram menores suscetibilidades erosivas, sinalizando que a intensidade da intervenção humana por sobre os espaços que apresentam diferenciações em sua constituição devem pautar-se pelos condicionantes que os mesmos possuem a partir de suas fragilidades ambientais.

Por fim, entende-se que estudos dessa natureza devem ser mais frequentes, pois, as análises de suscetibilidade a erosão hídrica são fundamentais para o planejamento agrícola e ambiental, identificando as áreas de maior vulnerabilidade e as medidas mais adequadas para sua ocupação e preservação.

\section{REFERÊNCIAS}

ARMENTERAS, D.; MURCIA, U.; GONZÁLEZ, T. M.; BARÓN, O. J.; ARIAS, J. E. Scenarios of land use and land cover change for NW Amazonia: Impact on forest intactness. Global Ecology and Conservation, v. 17, n. 1, p. 1-13, 2009.

BERTONI, J.; LOMBARDI NETO, F. Conservação do Solo. 4. ed. São Paulo: Editora Ícone, 1999. $355 \mathrm{p}$.

BRASIL. Lei n. 12.651, de 25 de maio de 2012. Dispõe sobre a proteção da vegetação nativa; altera as Leis nos 6.938, de 31 de agosto de 1981, 9.393, de 19 de dezembro de 1996, e 11.428, de 22 de dezembro de 2006; revoga as Leis nos 4.771, de 15 de setembro de 1965, e 7.754, de 14 de abril de 1989, e a Medida Provisória no 2.166-67, de 24 de agosto de 2001; e dá outras providências. 2012. Diário Oficial da União, Brasília, DF, Ano CXLIX, n. 102, 28 maio 2012. Seção 1, p.1. Disponível em: http://www.planalto.gov.br/ccivil 03/ ato2011-2014/2012/lei/112651.htm. Acesso em: 10 jun. 2020 .

CALDAS, V. I. S. P.; SILVA, A. S.; SANTOS, J. P. C. Suscetibilidade a Erosão dos Solos da Bacia Hidrográfica Lagos -São João, no Estado do Rio de Janeiro - Brasil, a partir do Método AHP e Análise Multicritério. Revista Brasileira de Geografia Física, v. 12, n. 4, p. 1415-1430, 2019.

CHALISE, D; KUMAR, L. 2020. Land use change affects water erosion in the Nepal Himalayas. PLOS ONE, v. 15, n. 4, p. 1-19, 2020. 
CLIMATE DATA. Clima Boa Esperança, Brasil. Disponível em: https://pt.climatedata.org/america-do-sul/brasil/minas-gerais/boa-esperanca-24987/. Acesso em: 16 jun. 2020.

CORRÊA, E. A.; MORAES, I. C.; PINTO, S. A. F.; LUPINACCI, C. M. Perdas de Solo, Razão de Perdas de Solo e Fator Cobertura e Manejo da Cultura de Cana-de-Açúcar: Primeira Aproximação. Revista do Departamento de Geografia, v. 32, n. 2, p. 72-87, 2016.

CPRM. SERVIÇO GEOLÓGICO DO BRASIL. Mapa geológico do estado de Minas Gerais. Porto Alegre: CPRM, escala 1:500.000. 2014.

. Relatório $\mathbf{N}^{0}$ 1. Acompanhamento da Estiagem na Região Sudeste do Brasil. Área de atuação da Superintendência Regional da CPRM de São Paulo. São Paulo, 2017.

DOMAZETOVIĆ, F.; ŠILJEG, A.; LONČAR, N.; MARIĆ, I. Development of automated multicriteria GIS analysis of gully erosion susceptibility. Applied Geography, v. 112, n. 1, p. 1-12, 2019.

EMBRAPA. EMPRESA BRASILEIRA DE PESQUISA AGROPECUÁRIA. Sistema Brasileiro de Classificação de Solos. 5. ed. Rio de Janeiro: Embrapa Solos, 2018. 353p.

ESRI. Environmental Systems Research Institute. ArcGIS Professional GIS for the desktop [computer program]. Version 10.5. Redlands, CA: Environmental Systems Research Institute. 2017. Fang, H. Impact of land use changes on catchment soil erosion and sediment yield in the northeastern China: A panel data model application. International Journal of Sediment Research, v. 35, n. 5, p. 540-549, 2020.

GONTIJO, G. A. B.; BORGES, L. A. C.; LAUDAReS, S. S. A.; BARros, V. C. C. Análise do atendimento ao Código Florestal e a regularização ambiental por unidades de bacias hidrográficas. Ciência Florestal, v. 29, n. 4, p. 1538-1550, 2019.

HAMADOUCHE, M. A.; DAIKH, F. Z.; CHRAIR, M.; ANTEUR, D.; FEKIR, Y.; DRISS, M. Erosion Sensitivity Mapping Using GIS-Based Multicriteria Analysis - Case Study of the Semiarid Macta Watershed, North-West of Algeria. In: KALLEL, A.; ERGUILER, Z. A.; CUI, Z. D.; KARRECH, A.; KARAKUS, M.; KULATILAKE, P.; SHUKLA, S. K. (Eds.). Recent Advances in Geo-Environmental Engineering, Geomechanics and Geotechnics, and Geohazards. Cham: Springer, p. 477-480, 2019.

MINAS GERAIS. Decreto $\mathbf{n}^{\mathbf{0}}$ 42.596/2002 de 23/05/2002. 2020. Institui o comitê da Bacia Hidrográfica do entorno do Reservatório De Furnas e dá outras providências. Diário do executivo, Belo Horizonte, Minas Gerais, 23 mai. 2002. Disponível em: https://leisestaduais.com.br/mg/decreton-42596-2002-minas-gerais-institui-o-comite-da-bacia-hidrografica-do-entorno-do-reservatorio-defurnas-e-da-outras-providencias. Acesso em: 17 mai. 2020.

MINAS GERAIS. Decreto no 44.520, de 16 de maio de 2007. Cria o Parque Estadual Serra da Boa Esperança, e declara de utilidade pública, para desapropriação de pleno domínio, os imóveis a que se refere, no município de Boa Esperança. Diário do executivo, Belo Horizonte, Minas Gerais, 16 mai. 2007. Disponível em: http://www.siam.mg.gov.br/sla/download.pdf. Acesso em: 20 jun. 2020.

NARRA, P.; COELHO, C.; SANCHO, F. Multicriteria GIS-based estimation of coastal erosion risk: Implementation to Aveiro sandy coast, Portugal. Ocean ; Coastal Management, v. 178, n. 1, p. 19, 2019. 
OGATO, G. S.; BANTIDER, A.; ABEBE, K.; GENELETTI, D. Geographic information system (GIS)-Based multi-criteria analysis of flooding hazard and risk in Ambo Town and its watershed, West shoa zone, oromia regional State, Ethiopia. Journal of Hydrology: Regional Studies, v. 27, n. 1, p. 56-64, 2020.

PASSOS, B. P.; KLOCK, A. B. Análise comparativa do antigo e o Novo Código Florestal: progresso ou retrocesso? Revista Direito Ambiental e sociedade, v. 9, n. 2, p. 299-316, 2019.

PIMENTEL, D.; BURGESS, M. Soil Erosion Threatens Food Production. Agriculture, v. 3, n. 3, p. 443-463, 2013.

PINTO, V. G.; LIMA, R. N. S.; RIBEIRO, C. B. M.; MACHADO, P. J. O. Diagnóstico físicoambiental como subsídio a identificação de áreas vulneráveis à erosão na bacia hidrográfica do Ribeirão do Espírito Santo, Juiz de Fora (MG), Brasil. Revista Ambiente e Água, v. 9, n. 4, p. 632646, 2014.

PROJETO MAPBIOMAS. Coleção 2 da Série Anual de Mapas de Cobertura e Uso de Solo do Brasil. Disponível em: http://mapbiomas.org. Acesso em: 29 mai. 2020.

SPAROVEK, G.; VAN-LIER Q. J.; DOURADO-NETO, D. Computer-assisted Köppen climate classification: a case study for Brazil. International Journal of Climatology, v. 27, n. 2, p. 257-266, 2007.

SPAROVEK, G.; BARRETO, A.; KLUG, I.; PAPP, L.; LINO, J. A revisão do Código Florestal brasileiro. Novos estudos, v. 89, n. 2, p. 111-135, 2011.

UFV - UNIVERSIDADE FEDERAL DE VIÇOSA; CETEC-MG. - FUNDAÇÃO CENTRO TECNOLÓGICO DE MINAS GERAIS; UFLA - UNIVERSIDADE FEDERAL DE LAVRAS; FEAM - FUNDAÇÃO ESTADUAL DO MEIO AMBIENTE. Mapa de Solos Do Estado de Minas

Gerais: legenda expandida. Belo Horizonte, Fundação Estadual do Meio Ambiente, escala $1: 650.000,2010$.

VAlladARES, G. S.; GOMES, A. S.; TORRESAN, F. E.; RODRIGUES, C. A. G.; GREGO, C. R. Modelo multicritério aditivo na geração de mapas de suscetibilidade à erosão em área rural. Pesquisa Agropecuária Brasileira, v. 47, n. 9, p. 1376-1383, 2012.

WEI, S.; ZHANG, X.; MCLAUGHLIN, N. B.; CHEN, X.; JIA, S.; LIANG, A. Impact of soil water erosion processes on catchment export of soil aggregates and associated SOC. Geoderma, v. 294, n. 1, p. 63-69, 2017. 